\title{
Planejamento e aprendizagem docente durante o estágio curricular supervisionado
}

Eliane Aparecida dos Santos elianedosantos0@gmail.com orcid.org/0000-0002-8992-8483 Programa de Pós-Graduação em Ensino de Ciências e Educação Matemática PPGECEM Universidade Estadual de Ponta Grossa (UEPG), Ponta Grossa, Paraná, Brasil

\section{Leila Inês Follmann Freire} leilaiffreire@msn.com orcid.org/ 0000-0002-6679-411X Universidade Estadual de Ponta Grossa (UEPG), Paraná, Brasil

\section{RESUMO}

O presente trabalho objetiva evidenciar o processo de construção da aprendizagem da docência sobre as orientações para o ensino, a compreensão das ideias dos estudantes e o repertório de estratégias instrucionais e avaliativas de professoras em formação durante o período de Estágio Curricular Supervisionado. Analisamos, com apoio da metodologia de análise de conteúdo, a percepção e as reflexões de três estagiárias sobre o ensino do conteúdo Cinética Química a partir de atividades de planejamento como o plano de aula, CoRe (Representação de Conteúdo) e o MRPA (Modelo de Raciocínio Pedagógico e Ação). As categorias utilizadas na análise foram definidas a priori, a saber: Orientações para o Ensino de Ciências, Conhecimento das Estratégias Instrucionais, Conhecimento da Avaliação do Ensino de Ciências e Conhecimento da Compreensão dos alunos sobre Ciências. Como principais resultados apontamos que os instrumentos de planejamento do ensino foram capazes de revelar a maioria das categorias do Conhecimento Pedagógico do Conteúdo (PCK). Ao analisar os instrumentos de registro do Estágio Curricular Supervisionado percebe-se que a prática de ensino desenvolvida proporcionou a iniciação à prática da docência, oportunizando relacionar a teoria e a prática com a realidade cotidiana escolar e os desafios que o professor enfrenta em sala de aula.

PALAVRAS-CHAVE: Estágio Curricular Supervisionado. Cinética Química. Conhecimento Pedagógico de Conteúdo. 


\section{INTRODUÇÃO}

O Estágio Curricular Supervisionado é um processo de aprendizagem em que o licenciando se aproxima da realidade de sua futura profissão. É extremamente necessária essa etapa, por ser uma oportunidade de conhecer o ambiente escolar in loco e também, por ser o estagiário orientado por professores experientes a respeito das atividades exercidas nesse período, possibilitando a construção de uma fundamentação teórico-prática necessária ao exercício da docência.

Como preparação à realização da prática docente, o estágio obrigatório nos cursos de Licenciatura tradicionalmente é constituído pelas atividades de reconhecimento da realidade escolar, observações e intervenções em aula (comumente chamadas de regências de classe).

O reconhecimento da realidade escolar é a caracterização da escola, na perspectiva de que esta instituição já constitui um espaço, uma história e um contexto. Nessa atividade de reconhecimento escolar, o estagiário pode aprender sobre os princípios e objetivos da escola, as características da estrutura física que afetam diretamente a ação docente em sala de aula, a organização e o funcionamento diário da escola, características pedagógicas, da comunidade escolar e do entorno, de modo a preparar-se para atuar com os alunos daquela instituição. Para a aprendizagem da docência enquanto profissão, o reconhecimento da realidade escolar possibilita identificar relações existentes entre os sujeitos envolvidos na escola e modos de organização institucional que poderão ser encontrados na vida profissional.

As observações de aulas contribuem para identificar os comportamentos de alunos e professores nos processos de ensino e aprendizagem, bem como perceber a relação professor-aluno, os métodos e técnicas utilizadas e os fenômenos ocorridos em sala de aula. Torna-se uma prática essencial ao estagiário, por apresentar um exemplo de prática profissional que pode ser problematizado em suas análises. Enquanto observa aulas e o processo de reflexão sobre essas observações, o estagiário pode aprender sobre como agir em determinadas situações, como trabalhar com dificuldades de aprendizagem, metodologias e estratégias de ensino que se adequam melhor a cada conteúdo e turma, como resolver conflitos, como estabelecer relações interpessoais com colegas de profissão e alunos.

A regência de classe é o momento em que o estagiário estará ministrando as aulas, com um conteúdo definido junto aos professores (supervisor e orientador), mas estando sob responsabilidade do estagiário planejar as aulas, definir a metodologia de ensino a ser trabalhada, desenvolver as atividades em classe e avaliar a aprendizagem dos estudantes, enfim é a etapa em que ele assume o papel do professor, ainda que sob supervisão e orientação externa. O período de regências de classe contribui para o desenvolvimento de diversos elementos fundantes da profissão professor, aliando teoria e prática de modo a propiciar o desenvolvimento de habilidades e competências próprias ao processo de ensino de conteúdos, de estabelecimento de relações pessoais e profissionais com os diversos sujeitos relacionados ao processo ensino-aprendizagem.

Na prática das atividades do estágio, o estagiário pode refletir sobre os pontos positivos e negativos encontrados em sala de aula, visando ter uma maior compreensão sobre a mesma. Para Pimenta e Lima (2008), o aprendizado de 
qualquer profissão é prático e esse conhecimento pode ocorrer a partir de observação, em que o futuro professor irá repetir aquilo que ele avalia como bom ou viável, resultando num processo de escolhas.

Tudo isso é um grande desafio, pois durante o estágio o licenciando aprende na prática sobre o convívio da sala de aula, tendo a responsabilidade de planejar como serão as aulas ministradas por ele, qual metodologia de ensino será utilizada, a organização das aulas, quanto ao tempo e as atividades realizadas com os alunos, de que forma serão feitas as explicações e como será feita a verificação do aprendizado dos alunos.

Dentre as aulas ministradas pelo estagiário podem ocorrer diversas situações como, por exemplo, indisciplina dos alunos e falta de materiais. Diante disso, cabe ao estagiário aprender como solucionar esses problemas que também ocorrem ao longo da prática profissional de professores já formados.

Então, o estágio supervisionado apresenta ao futuro professor a realidade do seu cotidiano de trabalho, possibilitando aprender quais são as metodologias de ensino mais eficazes em determinados contextos e grupos de alunos, como se comportar diante dos alunos e perante as várias situações que ocorrem em sala e como atingir o objetivo de aprendizagem. Essa prática amplia o entendimento sobre a escola e as responsabilidades designadas ao professor.

Pimenta (2001) ressalta que a formação do professor a partir da observação e reprodução da prática modelar, é a valorização do sucesso com aproximação do que foi observado. Com isso, gera-se a conservação de "modismos", mesmos hábitos, valores e comportamentos no geral. Assim, o estágio reduz-se a copiar os modelos já existentes, sem fazer uma análise crítica fundamentada no processo de ensino atual. Para uma formação para a docência mais adequada ao desenvolvimento da prática profissional, o estágio da licenciatura precisa ir além da cópia de modelos de prática, chegando à investigação da reflexão sobre a ação docente.

Para modificar essa realidade de reprodução da prática modelar, busca-se um desenvolvimento de qualidade no planejamento. No modo mais comum de planejar a prática de ensino dos professores, guiado por formulários préestabelecidos, conteúdos, estratégias de ensino, avaliação, entre outras, percebese um trabalho mecânico, que pode ser repetido pelos professores em sua prática docente por vários anos.

Considerando que é desejável que os professores sejam mais críticos e criativos em relação aos conteúdos e formas de ensinar, é premente que se desenvolvam métodos e encaminhamentos mais abrangentes à realidade dos alunos que frequentam a instituição escolar atual.

Para Andrade e Fernandez (2008), o planejamento organiza e facilita a forma de trabalhar em sala de aula. Se bem elaborado, o planejamento torna-se um instrumento de reflexão da própria prática e da autonomia aos professores. Mas alguns professores compreendem o plano de ensino como um mero documento em que constam os conteúdos conceituais ensinados durante o ano letivo. Sendo feito apenas em um momento e não durante todo o ano como um processo de reflexão de ensino-aprendizagem a partir da sua ação prática.

O planejamento é uma das etapas que o estagiário deve desenvolver no Estágio Curricular Supervisionado, a partir das atividades de reconhecimento 
escolar e observações em sala, dando início às suas regências de classe. Nesse momento de planejamento de aulas, o estagiário define os objetivos propostos para cada aula, como será o desenvolvimento das atividades e explicações aos alunos, qual metodologia e estratégia aplicará, quais os recursos didáticos que serão utilizados e seus critérios de avaliação. Para elaborar esse plano de ensino, o estagiário dispõe de seus conhecimentos construídos ao longo do curso de Licenciatura e também na sua vivência escolar.

Neste trabalho analisamos o processo de desenvolvimento do planejamento para a execução de aulas de Química de três estagiárias, realizadas com alunos do $2^{\circ}$ ano do Ensino Médio em escolas públicas da cidade de Ponta Grossa-Paraná, sendo o conteúdo Cinética Química. O objetivo da investigação que realizamos é evidenciar o processo de construção da aprendizagem da docência pelas professoras em formação, especialmente a respeito de suas orientações para o ensino, compreensão das ideias dos estudantes e repertório de estratégias instrucionais e avaliativas.

As atividades desenvolvidas nas intervenções do estágio curricular em foco neste trabalho permeavam um processo de planejamento inicial com o professor orientador da universidade, em parceria com o professor supervisor da escola, e eram guiados por alguns instrumentos específicos, como o modelo de plano de aula e o CoRe (instrumento de Representação de Conteúdo, construído individualmente pelo professor em formação para situar sua compreensão pessoal sobre o conteúdo a ser ensinado nas aulas). Esse instrumento é amplamente empregado na literatura como ferramenta de acesso ao Conhecimento Pedagógico de Conteúdo (PCK) de professores (LEAL; NOVAIS; FERNANDEZ, 2015). Durante a realização das regências de classe as licenciandas (sujeitos de pesquisa nesta investigação) escreveram diários de professor (PORLÁN; MARTIN, 1997). Ao final das atividades organizaram seus portfólios de estágio com a inclusão do Modelo de Raciocínio Pedagógico e Ação (MRPA) para o conjunto de aulas ministradas.

\section{CONHECIMENTO PEDAGÓGICO DE CONTEÚDO (PCK)}

A literatura internacional, em especial da área de ensino de ciências, tem apontado uma base de conhecimentos para professores que delimita e caracteriza essa profissão (FERNANDEZ, 2015). Dentre estes, recebe destaque o conceito de Conhecimento Pedagógico do Conteúdo, PCK, do inglês Pedagogical Content Knowledge, e que representa o conhecimento próprio do professor utilizado no processo de ensino, que se constitui a partir da integração do conteúdo específico de uma disciplina com pressupostos da pedagogia.

O PCK ganhou repercussão no campo do desenvolvimento profissional docente e diversos estudos buscaram investigar sua constituição, seu desenvolvimento e as formas de acessá-lo (GROSSMAN, 1990; MAGNUSSON; KRAJCIK; BORKO, 1999; PARK; OLIVER, 2008; ROLLNICK et al., 2008). Nesse campo de pesquisas, foram apresentados alguns modelos que tentavam identificar e representar os componentes do PCK, entre eles temos a contribuição dada por Magnusson, Krajcik e Borko (1999), que enfatiza os componentes do PCK para o Ensino de Ciências, definido a partir de cinco componentes: orientações para o ensino de ciências; conhecimento do currículo; conhecimento da avaliação; 
conhecimento sobre os alunos; e conhecimento das estratégias instrucionais (figura 1).

Figura 1: Componentes do Conhecimento Pedagógico do Conteúdo para o Ensino de Ciências

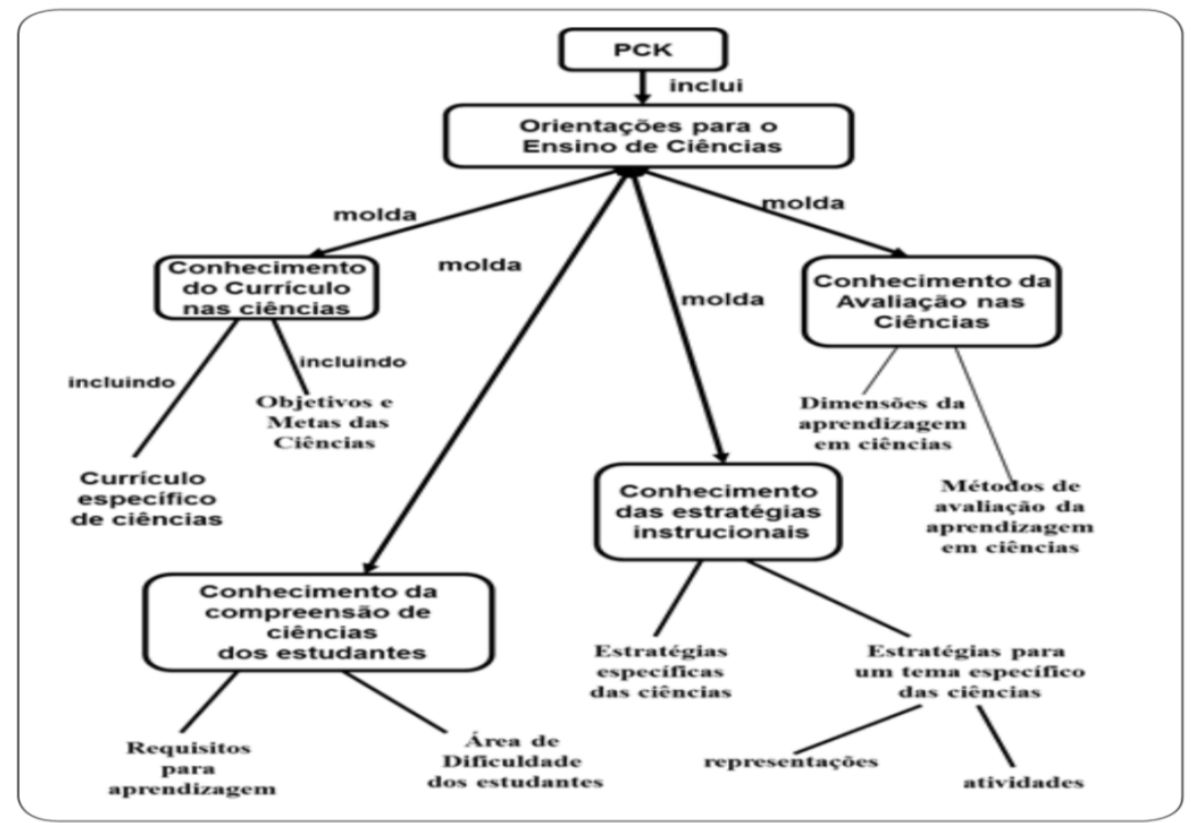

Fonte: Magnusson, Krajcik e Borko (1999).

Os componentes de conhecimento do professor sobre o currículo, a avaliação, as estratégias instrucionais e a compreensão dos estudantes são moldados pelas orientações para o ensino de ciências que o docente possui. Magnusson, Krajcik e Borko (1999) propuseram nove diferentes orientações: processo, rigor acadêmico, didática e mudança conceitual; atividade dirigida; descoberta; ciência baseada em projetos; investigação; e investigação dirigida (quadro 1).

Cada orientação foi descrita com relação aos objetivos do ensino de ciências que um professor com aquela orientação possui e as características típicas da instrução a serem conduzidas por um professor com uma dada orientação.

Quadro 1: Características das Orientações para o Ensino de Ciências

\begin{tabular}{|c|c|c|}
\hline 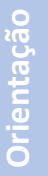 & $\begin{array}{l}\text { Objetivos do ensino } \\
\text { de Ciências }\end{array}$ & Características da instrução \\
\hline 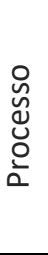 & $\begin{array}{c}\text { Ajudar os estudantes a } \\
\text { desenvolver as } \\
\text { "habilidades para o } \\
\text { processo da ciência" }\end{array}$ & $\begin{array}{l}\text { Professor apresenta aos alunos o processo de } \\
\text { raciocínio empregado pelos cientistas para } \\
\text { adquirir novos conhecimentos. Os alunos } \\
\text { participam em atividades que desenvolvem o } \\
\text { processo de pensamento e habilidades de } \\
\text { pensamento integradas. }\end{array}$ \\
\hline
\end{tabular}




\begin{tabular}{|c|c|c|}
\hline 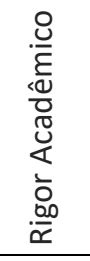 & $\begin{array}{l}\text { Representar um } \\
\text { determinado campo da } \\
\text { ciência (exemplo: } \\
\text { química) }\end{array}$ & $\begin{array}{c}\text { São utilizados trabalhos de laboratórios e } \\
\text { demonstrações para verificar os conceitos } \\
\text { científicos demonstrando a relação entre } \\
\text { determinados conceitos e os fenômenos. Os } \\
\text { alunos são desafiados em problemas e } \\
\text { atividades difíceis. }\end{array}$ \\
\hline 芯 & $\begin{array}{c}\text { Transmitir os fatos da } \\
\text { ciência }\end{array}$ & $\begin{array}{l}\text { O professor apresenta a informação, geralmente } \\
\text { através de palestra ou discussão e as perguntas } \\
\text { direcionadas aos alunos têm o propósito de } \\
\text { fornecer um suporte justificável para o } \\
\text { conhecimento dos fatos produzidos pela ciência. }\end{array}$ \\
\hline 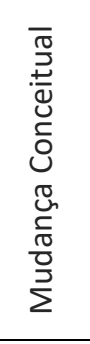 & $\begin{array}{l}\text { Facilitar o } \\
\text { desenvolvimento do } \\
\text { conhecimento científico } \\
\text { através do confronto } \\
\text { dos estudantes com um } \\
\text { contexto para explicar } \\
\text { que desafia suas } \\
\text { concepções ingênuas. }\end{array}$ & $\begin{array}{l}\text { Estudantes são pressionados a respeito de sua } \\
\text { visão sobre o mundo e levados a considerar a } \\
\text { adequação das explicações alternativas. O } \\
\text { professor facilita a discussão e o debate } \\
\text { necessário para estabelecer as asserções de } \\
\text { conhecimento validado. }\end{array}$ \\
\hline 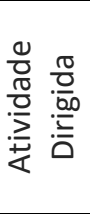 & $\begin{array}{l}\text { Permitir que os } \\
\text { estudantes sejam ativos } \\
\text { com o uso de materiais } \\
\text { e experimento do tipo } \\
\text { "mão-na-massa". }\end{array}$ & $\begin{array}{l}\text { Os estudantes participam em atividades do tipo } \\
\text { "mão-na-massa" utilizadas para verificação ou } \\
\text { descoberta. }\end{array}$ \\
\hline 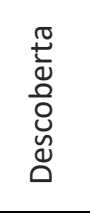 & $\begin{array}{l}\text { Fornecer oportunidade } \\
\text { aos estudantes para } \\
\text { descobrir alguns } \\
\text { conceitos científicos } \\
\text { alvos. }\end{array}$ & $\begin{array}{l}\text { Centrada-no-aluno. Os alunos exploram o } \\
\text { mundo natural seguindo seus próprios } \\
\text { interesses e descobrem padrões de como o } \\
\text { mundo funciona durante suas explorações. }\end{array}$ \\
\hline 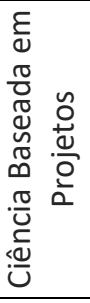 & $\begin{array}{l}\text { Envolver os estudantes } \\
\text { na busca de soluções } \\
\text { para problemas reais. }\end{array}$ & $\begin{array}{l}\text { Centrada-no-projeto. A atividade de professores } \\
\text { e estudantes é centrada numa questão que } \\
\text { organiza os conceitos e os princípios e direciona } \\
\text { as atividades dentro de um tópico de estudo. } \\
\text { Através da investigação, os alunos desenvolvem } \\
\text { uma série de artefatos (produtos) que refletem } \\
\text { suas compreensões. }\end{array}$ \\
\hline 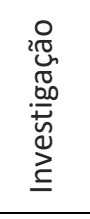 & $\begin{array}{l}\text { Representar a ciência } \\
\text { como uma pesquisa, } \\
\text { investigação. }\end{array}$ & $\begin{array}{l}\text { Centrada-na-investigação. O professor apoia os } \\
\text { alunos na definição e investigação dos } \\
\text { problemas, no esboço das conclusões e na } \\
\text { avaliação da validade do conhecimento a partir } \\
\text { de suas conclusões. }\end{array}$ \\
\hline 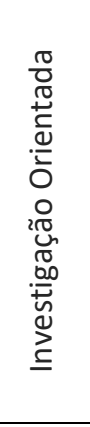 & $\begin{array}{l}\text { Constituir uma } \\
\text { comunidade de } \\
\text { aprendizes, cujos } \\
\text { membros partilham a } \\
\text { responsabilidade de } \\
\text { compreender o mundo } \\
\text { físico, especialmente do } \\
\text { que diz respeito ao uso } \\
\text { das ferramentas da } \\
\text { ciência. }\end{array}$ & $\begin{array}{l}\text { Centrada-na-comunidade-de-aprendizagem. O } \\
\text { professor e os estudantes participam na } \\
\text { definição e investigação dos problemas, na } \\
\text { determinação dos padrões, inventando e } \\
\text { testando explicações e avaliando a utilidade e } \\
\text { validade de seus dados e a adequação de suas } \\
\text { conclusões. O professor apoia os alunos em } \\
\text { utilizar os materiais e as ferramentas } \\
\text { intelectuais da ciência para o uso independente } \\
\text { dela. }\end{array}$ \\
\hline
\end{tabular}

Fonte: Magnusson, Krajcik e Borko (1999), tradução Fernandez (2014, p. 329). 
INSTRUMENTO DE ACESSO AO PCK: CORE (REPRESENTAÇÃO DE CONTEÚDO)

O CoRe (do inglês Content Representation) é um instrumento de Representação de Conteúdo para acessar o PCK, baseado na proposta de Loughran et al. (2000) e Loughran, Mulhal e Berry (2004). É formado por oito perguntas, listadas na sequência, que são respondidas pelo professor após definir as ideias principais (grandes ideias) de um conteúdo específico.

1. O que você quer que os estudantes aprendam com esta ideia?

2. Por que é importante para os estudantes aprenderem esta ideia?

3. O que mais você sabe sobre esta ideia?

4. Quais são as dificuldades e limitações ligadas ao ensino desta ideia?

5. Que conhecimento sobre o pensamento dos estudantes tem influência no seu ensino sobre esta ideia?

6. Que outros fatores influem no ensino desta ideia?

7. Que procedimentos/estratégias você emprega para que os alunos se comprometam com esta ideia?

8. Que maneiras específicas você utiliza para avaliar a compreensão ou a confusão dos alunos sobre esta ideia?

Esse é um instrumento diagnóstico que busca alcançar a compreensão do professor sobre um conteúdo específico e representar este conhecimento de uma forma compreensível e visível a outros professores. O CoRe é tanto uma ferramenta de pesquisa para acessar a compreensão sobre o ensino de um conteúdo, como uma estratégia para estimular o raciocínio pedagógico do professor e promover uma possível ampliação do seu PCK.

O CoRe pode ser realizado em forma de questionário ou entrevista, podendo ser confeccionado individualmente ou em grupo. As respostas fornecidas pelos professores para as questões do CoRe podem revelar indícios de seu PCK sobre um conteúdo específico e a partir da análise criteriosa dessas respostas esses indícios podem ser observados e documentados (JUNIOR, NOVAIS, FERNANDEZ, 2012).

\section{MODELO DE RACIOCÍNIO PEDAGÓGICO E AÇÃO DE SHULMAN (1987)}

Durante todo o estágio, objeto de estudo deste trabalho, as licenciandas escreveram diários de professor (PORLÁN; MARTIN, 1997), quando registraram suas percepções sobre as aulas e reflexões sobre o processo de ensinoaprendizagem.

No estágio, as licenciandas organizaram portfólios de todas as ações desenvolvidas, posteriormente utilizado como ferramenta de avaliação da disciplina, nos portfólios destacamos a inclusão do Modelo de Raciocínio Pedagógico e Ação (MRPA) para o conjunto de aulas ministradas.

O MRPA foi proposto por Shulman (1987) e representa o modo como o professor implementa a compreensão, representação e o desenvolvimento do 
processo de ensino. Para Shulman, a maior parte dos processos de ensino iniciam por alguma forma de "texto", um livro didático, um roteiro ou outro tipo de material que o professor ou os estudantes gostariam de compreender. Segundo esse modelo então, dado um texto didático, objetivos educacionais, e um conjunto de ideias, o raciocínio pedagógico e a ação envolvem um ciclo através de atividades de compreensão, transformação, instrução, avaliação e reflexão. O ponto de partida e término do processo é um ato de compreensão.

Este modelo apresenta os processos das ações educativas, mostra como os conhecimentos são acionados, relacionados e construídos durante o ensino e a aprendizagem. O modelo é formado por seis processos interativos que se relacionam, são eles: compreensão, transformação, instrução, avaliação, reflexão e nova compreensão, sendo a nova compreensão o fruto de todo o processo e o reinício de um novo ciclo (Figura 2).

Para maior compreensão do MRPA apresentamos uma descrição de suas principais etapas e como se desenvolvem.

Compreensão: A compreensão é o ponto de partida do processo, para ensinar é necessário compreender o modo que uma ideia se relaciona com outras na matéria e mesmo fora dela.

Os professores deveriam gerar formas alternativas de lidar com suas disciplinas, análises, ilustrações, metáforas, exemplos, experimentos, simulações, dramatizações, músicas, filmes, demonstrações, etc., que levem em consideração diferentes habilidades, conhecimentos prévios e estilos de aprendizagem de seus alunos (MIZUKAMI, 2004, p. 8).

Transformação: Uma vez compreendidas as ideias, elas devem ser transformadas para ensinar. 0 processo de transformação requer certo grau de combinação dos seguintes subprocessos, cada um com seu tipo de repertório: 1) Preparação - é necessário preparar o material (texto, livro didático, apostila etc.) em um processo de interpretação crítica; 2) A apresentação de suas ideias em forma de novas analogias, metáforas etc.; 3) Seleções didáticas entre os métodos ou modelos de ensino; 4) Adaptações dessas representações a características gerais tanto dos alunos como do que se vai ensinar; 5) Adaptação das representações e das características específicas de cada aluno da classe de aula. Estas formas de transformação se constituem na essência do ato de raciocinar pedagogicamente, do ensino como raciocínio e do planejamento da ação docente. 
Figura 2- Modelo de Raciocínio Pedagógico e Ação Proposto por Shulman

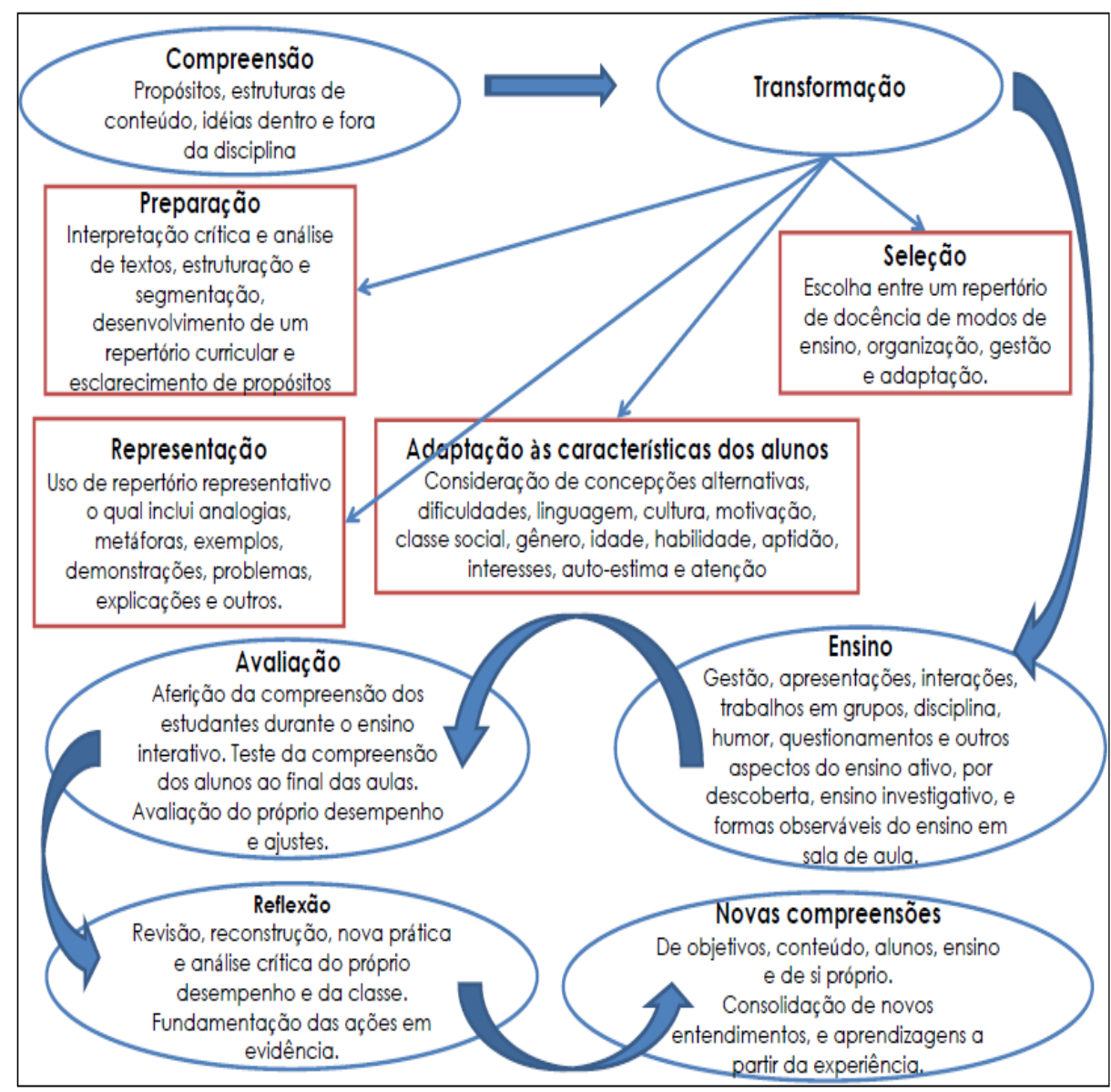

Fonte: Adaptado de Salazar (2005).

Ensino: A abordagem para aquele conteúdo, trabalhos em grupo, disciplina, formulação de perguntas, o ensino por investigação e outras formas de ensino.

Avaliação: Este processo inclui tanto o controle imediato das compreensões e interpretações dos alunos como exames mais formais, ou seja, tanto ocorre durante como após a instrução. A comprovação desse entendimento requer a interação de todas as formas de compreensão e transformação próprias do professor. Para compreender o que um aluno aprendeu é preciso entender profundamente o material que foi utilizado para o ensino e os processos de aprendizagem.

Reflexão: É a análise retrospectiva do que o professor fez no processo de ensino e aprendizagem. É através desse processo que o profissional aprende sobre a experiência, a reflexão pode acontecer de forma independente ou em conjunto. Um aspecto fundamental desse processo será uma revisão do ensino em comparação com os objetivos que se procurava alcançar.

Nova Compreensão: É um novo começo, é esperado que mediante o ensino o professor adquira uma nova compreensão dos seus objetivos, dos materiais que utilizou para ensinar, dos alunos e dos processos didáticos. A nova compreensão não se produz automaticamente, pois para que ela aconteça são necessárias estratégias específicas de documentação, análises e debates. 
Shulman (1987) afirma que os processos no Modelo de Raciocínio Pedagógico e Ação não são necessariamente sequenciais, podendo aparecer em ordem distinta ou alguns nem aparecerem durante alguns atos de ensino. Um professor deveria ser capaz de demonstrar que pode participar desses processos, a formação docente deveria proporcionar aos licenciandos as formas de compreensão e destrezas do desempenho que eles requerem para progredir mediante o raciocínio pedagógico, levando-os a executar um ciclo completo, como o apresentado no modelo.

Salazar (2005), a partir dos processos propostos no modelo de Shulman, propôs uma representação para o mesmo (figura 2) e afirma que:

Este modelo supõe que a docência inicia desde que a pessoa pense como vai atuar em um processo educativo. Este modelo de caráter cíclico e dinâmico toma como ponto de partida a reflexão do ato docente, desde as intenções educativas, a estrutura conceitual e as ideias que circundam dentro e fora da disciplina que vai ensinar. (...) Estas compreensões permitem a transformação dos conteúdos disciplinares em formas representativas que permitem o seu ensino, sua avaliação, sua reflexão e novas compreensões para um futuro no qual se inicia um novo ciclo. (SALAZAR, 2005, p.6).

\section{O ENSINO DE CINÉTICA QUÍMICA}

Em uma aula de Química, podemos explorar o conhecimento dos alunos, a relação entre conhecimentos de senso comum e científico. Nessa perspectiva, o ensino de Cinética Química aborda a velocidade das reações químicas, os fatores que influenciam nela e compreende a ocorrência e os mecanismos das reações permitindo o entendimento de diversos processos que envolvem o cotidiano do aluno, como a ação dos medicamentos, a digestão dos alimentos, entre outros exemplos. É um tema que tem grande importância na indústria, na produção de remédios, no corpo humano, entre outras áreas (KLINGER; BARICCATTI, S/D).

Muitas vezes as atividades didáticas desenvolvidas no ensino de cinética química são basicamente aulas expositivas, que não levam em consideração os conhecimentos prévios e nem o cotidiano do aluno. Com isso, baseado na proposta da escola em formar cidadãos atuantes e conscientes, é necessário o aluno dispor de informações conceituais que o auxiliem a compreender o conhecimento científico e o avanço tecnológico da sociedade de forma articulada ao seu cotidiano.

\section{METODOLOGIA}

Esta investigação é uma pesquisa qualitativa (BOGDAN; BIKLEN, 1994), que se caracteriza nesta pesquisa pela análise do processo de planejamento de três estagiárias que escolheram o tema Cinética Química para o desenvolvimento das regências de classe da disciplina de Estágio Curricular Supervisionado do curso Licenciatura em Química da Universidade Estadual de Ponta Grossa, Paraná. O estágio foi realizado em duas escolas da rede estadual de ensino do município de Ponta Grossa/PR, com duas turmas de segundo ano do Ensino Médio.

As aulas ministradas foram realizadas com metodologias diferentes, tendo duas estagiárias (aqui designadas por L1 e L2) realizando regências em dupla na 
escola 1 (designada por E1). O estudo sobre o conteúdo Cinética Química foi planejado em 16 aulas ( 50 minutos cada) objetivando desenvolver a Alfabetização Cientifica e Técnica. A estagiária 3 (designada por L3) realizou as regências individualmente noutra escola (designada por E2), sendo o mesmo conteúdo desenvolvido em 12 aulas, com uma prática contextualizada com o cotidiano dos alunos, com o tema Automedicação.

Os dados disponíveis para serem utilizados nesta pesquisa envolvem os planos de aulas desenvolvidos para cada conjunto de aulas, o instrumento CoRe, confeccionado individualmente e o Modelo de Raciocínio Pedagógico e Ação (MRPA) de cada licencianda. Os dados foram analisados com aporte da metodologia de análise de conteúdo (BARDIN, 2003), com categorias definidas a priori a partir de quatro componentes do Modelo proposto por Magnusson, Krajcik e Borko (1999): Orientações para o Ensino de Ciências, Conhecimento das Estratégias Instrucionais, Conhecimento da Avaliação do Ensino de Ciências, Conhecimento da Compreensão dos alunos sobre Ciências, a qual se desdobra em duas subcategorias: Conhecimento dos Requisitos para a Aprendizagem e Conhecimento da Área de Dificuldade dos Estudantes.

\section{RESULTADOS E DISCUSSÕES}

O conteúdo de Cinética Química trabalhado pelas estagiárias foi decidido junto com as professoras supervisoras de cada escola a partir do Plano de Trabalho Docente de cada uma, sendo então organizados os planos de aulas, quais materiais seriam utilizados em sala, qual metodologia de ensino seria utilizada para mediar o conhecimento aos alunos e as estratégias e atividades usadas nas aulas.

As análises dos registros de todos os instrumentos de coleta de dados foram feitas separadamente para cada categoria do PCK considerada no trabalho. Na sequência apresentaremos os resultados dessas análises.

\section{ORIENTAÇÕES PARA O ENSINO}

Ao analisar o CoRe, as três licenciandas selecionaram como a grande ideia 1 os fatores que alteram a velocidade das reações. Na primeira questão do CoRe $(0$ que você quer que os estudantes aprendam com esta ideia?), as licenciandas destacaram:

L2: Compreender a Velocidade da reação e os fatores que a alteram. Reconhecer os fatores no seu cotidiano.

L3: A utilizar a química aprendida na escola no seu dia a dia, como por exemplo, utilizar os conceitos dos fatores que afetam as velocidades das reações para ao se deparar com uma torná-la mais rápida ou devagar de acordo com a necessidade. Além disso, eles deveriam conhecer como ocorre uma reação em nível microscópico, compreendendo que para que uma reação realmente ocorra é necessário aproximação, orientação específica e choque efetivo entre as moléculas, a nível macroscópico entender que existem indicações visuais da ocorrência de uma reação como surgimento de bolhas, alteração na coloração da solução, aparecimento de precipitado, entre 
outros, mas que há reações que não necessariamente possuam alterações visíveis, mas ainda assim configuram uma reação, e a nível simbólico interpretando a linguagem química escrita das reações, tais conceitos são fundamentais para percepção do que é a velocidade de uma reação e o que a torna mais vagarosa ou rápida. Compreender que a formação de produtos dáse por meio do rearranjo molecular dos átomos que constituem as moléculas dos reagentes. Eles deverão aprender a interpretar experimentos demonstrativos e como os fenômenos observados podem ser descritos microscópica e simbolicamente, e ainda saber manipular as vidrarias de laboratório em experimentos investigativos e utilizá-los como ferramenta para construção do seu próprio conhecimento. Gostaria que eles aprendessem como o aumento da temperatura afeta as moléculas de uma solução, aumentando o grau de agitação destas e consequentemente aumentando o choque efetivo entre elas. Como as moléculas estão organizadas em diferentes superfícies de contato, e que uma amostra pulverizada tem maior disponibilidade de moléculas para efetivar uma reação química. Como a diferença de pressão exercida aumenta o choque efetivo das moléculas aumentando a velocidade da reação, mas que isto é melhor aplicável a reações em que os reagentes estejam no estado gasoso. Revisar os conceitos de energia de ativação apreendidos para compreender os conceitos de catalisadores e inibidores de reações químicas e como e presença deles pode afetar a velocidade das reações mesmo sendo regenerado ao final da reação. Pretendo que os alunos entendam que a concentração dos reagentes ou produtos é um dos fatores que afetam as velocidades das reações, pois a maior concentração indica maior presença de moléculas para que a reação ocorra. Pretendo que eles consigam aplicar os conceitos apreendidos na resolução dos estudos de casos sobre automedicação.

As estagiárias L1, L2 e L3 atribuem a importância do seu ensino à compreensão da definição sobre os fatores que alteram a velocidade da reação. É possível observar para as estagiárias L2 e L3 a importância da compreensão dos conceitos em relação com o cotidiano do aluno. Ao analisar os planos de aulas e o MRPA, a mesma importância foi observada, sendo possível detectar nestes documentos o uso de experimentos investigativos (pelas licenciandas L1 e L2) e para L3 questões que envolvem o cotidiano, organizadas em torno do tema automedicação.

Considerando as nove orientações para o ensino de ciências propostas por Magnusson, Krajick e Borko (1999), constatamos que a prática pedagógica das estagiárias L1 e L2 segue as orientações "Descoberta" e "Investigação", pois atribuíram grande importância ao objetivo de permitir que os alunos trabalhassem ativamente no processo de construção do seu conhecimento, através de problemas investigativos e questões reflexivas.

A prática pedagógica da estagiária $L 3$, evidenciada a partir de seus planejamentos de aula, segue aspectos da orientação "Ciência Baseada em Projetos", julgando importante envolver os alunos com o tema, centrando-se no entendimento dos fatores que afetam a velocidade de uma reação a partir do tema automedicação, buscando ajuda de profissionais médicos para esclarecimentos sobre a automedicação e suas consequências no organismo. Na resposta dada no CoRe também encontramos indícios da presença da orientação "Processo" em L3, especialmente na referência feita aos níveis representacionais do conhecimento que a estagiária considera importante desenvolver. 


\section{CONHECIMENTO DA COMPREENSÃO DOS ALUNOS}

Esta categoria do PCK diz respeito às características, concepções alternativas e dificuldades de aprendizagem dos estudantes e apresenta duas subcategorias: 0 Conhecimento dos Requisitos para a Aprendizagem que corresponde ao entendimento que um professor tem sobre os saberes prévios necessários à aprendizagem, sua compreensão das diferentes abordagens dos estudantes para a aprendizagem, e como estes relacionam o desenvolvimento desse conhecimento dentro de um conteúdo particular. E a outra subcategoria, o Conhecimento da Área de Dificuldade dos Estudantes, consiste no conhecimento que os professores apresentam dos conceitos e tópicos de ciências que os estudantes encontram maior dificuldade durante sua aprendizagem (LEAL; NOVAIS; FERNANDEZ, 2015).

$\mathrm{Na}$ questão cinco do CoRe (Que conhecimento sobre o pensamento dos estudantes tem influência no seu ensino sobre esta ideia?), as estagiárias deram importância sobre o conhecimento prévio dos alunos para poder entender os conceitos de cinética química, como mostram os trechos a seguir:

L1: Entender reações químicas.

L2: Reconhecer uma reação química.

L3: Os alunos precisam compreender bem o modelo atômico, suas partículas, as partículas que interagem em uma reação química, como ela se efetiva através de ligações e interações. Precisam compreender os conceitos de concentração, temperatura, pressão, geralmente abordados na física, precisam compreender que as moléculas são feitas de átomos e que estas não estão paradas.

No CoRe, as licenciandas citam em suas respostas os conteúdos que os alunos devem ou deveriam ter aprendido, para poderem relacionar o conhecimento dentro do conteúdo de cinética química. Nos MRPAs, constatamos que as licenciandas deram importância à compreensão prévia dos alunos, levado em consideração as dúvidas, dificuldades e até mesmo o entusiasmo dos alunos para desenvolver as atividades propostas por elas. O mesmo não foi observado nos planos de aulas. Abaixo ilustramos a concepção da licencianda L3 em seu MRPA:

[...] Fizemos isso com o princípio de desenvolver a autonomia de pesquisa nos alunos. Porém notamos que ao avançar as atividades, os alunos começaram a ficar desinteressados e sem disposição. Então começamos a fazer adaptações, tentamos motivá-los, trouxemos materiais diferenciados [...] (L3)

\section{CONHECIMENTO DA AVALIAÇÃO NO ENSINO DE CIÊNCIAS}

Para a avaliação da compreensão dos fatores que alteram a velocidade das reações - ideia 1 , foi descrita no MRPA das estagiárias a realização de uma prova escrita. Na resposta à questão 8 do CoRe (Que maneiras específicas você utiliza para avaliar a compreensão ou a confusão dos alunos sobre esta ideia?) elas destacam outras formas de avaliação que oportunizam conhecer e analisar a evolução dos conceitos abordados: 
L2: Participação dos alunos nas aulas.

L3: Respostas a questões indagadas e questionamentos durante toda a aula; Aprofundamento das respostas aos problemas propostos e resolução dos exercícios. Criação do meio de divulgação do conteúdo trabalhado em sua comunidade escolar, entre outros.

\section{CONHECIMENTO DAS ESTRATÉGIAS INSTRUCIONAIS}

Na sétima questão do CoRe, as licenciandas são questionadas sobre quais procedimentos/estratégias podem ser empregados no ensino daquele conhecimento. As três estagiárias apontam o uso de experimentos, como mostram os trechos abaixo:

L1: Experimentos para que os alunos observem as reações.

L2: Experimentos investigativos, que envolva o cotidiano dos alunos.

L3: Utilização de experimentos demonstrativos e investigativos (para desenvolvimento do nível macroscópico nos alunos), de exposição dialogada e uso de analogias (para explicar a nível microscópico o observado) escrita de reações químicas (para representar o nível simbólico que acompanha as reações químicas), exposição dialogada para relacionar todos os conteúdos apreendidos, e quaisquer outros.

$\mathrm{Na}$ citação destacada, as licenciandas utilizam os experimentos como estratégia para a melhor compreensão dos alunos referente ao tema abordado os experimentos. A mesma importância é considerada nos planos de aulas e apontada no MRPA das estagiárias, como mostram os trechos de seus MRPA:

L1: Com o intuito de começar o processo de Alfabetização Científica, a sequência didática se iniciou com o "Show da Química", onde as professoras eram as mágicas e os alunos sendo os químicos que iriam revelar o segredo, sendo esse o problema investigativo, que seria discutido no decorrer das aulas.

L2: Após estar com esses materiais prontos, iniciamos as regências, começamos com a apresentação dos experimentos investigativos como uma mágica, em que os alunos seriam os químicos que desvendariam os segredos da mágica.

L3:O conteúdo deveria ser integralmente ministrado intercalando os três níveis, simbólico, macroscópico e microscópico, onde utilizou-se experimentos com medicamentos que representassem o nível macro, escrita de reações e linguagem química representando o simbólico e utilização de um modelo molecular confeccionado com bolinhas de isopor que tinham em uma extremidade afixado imãs para elucidação do nível micro.

De acordo com o referencial teórico adotado, a subcategoria Conhecimento da Estratégia de um Tema Específico de Ciências apresenta duas divisões: "Representações", que está relacionada ao conhecimento dos professores e "Atividades", que está relacionada aos conhecimentos das atividades úteis, aos alunos, na compreensão de conceitos específicos e suas relações, como, por exemplo: problemas, demonstrações, simulações, investigações ou experimentos. 
Foi possível identificar nos materiais das estagiárias o conhecimento específico de atividades para a aprendizagem dos alunos.

As discussões precedentes indicam que cada instrumento avaliativo elaborado no planejamento de ensino no estágio promoveu a ampliação no repertório profissional das estagiárias. Assim, a partir da análise do CoRe pode-se constatar que esse instrumento fornece elementos para os conhecimentos necessários ao professor, como a compreensão do conhecimento do conteúdo, domínio do conhecimento específico do aluno e da pedagogia. Esses conhecimentos são evidentes nos demais instrumentos de planejamento, embora em algumas das ações planejadas o conhecimento sobre a compreensão dos alunos fica menos evidente, como é o caso do plano de aula.

Quanto a licencianda E1, foi possível observar que embora não possua uma orientação única para ensino, como discutida anteriormente na categoria Orientações para o Ensino, ao analisar os instrumentos de planejamento, foi possível observar que ela valoriza o envolvimento e a participação dos alunos em aula e considera que o modo de avaliar deve ser contínuo durante o processo de ensino e aprendizagem, tanto o modo de ensino do professor, como a aprendizagem dos alunos. Suas aulas foram guiadas por questionamentos iniciais, priorizando o entendimento prévio dos alunos para posterior construção de conhecimentos. Nas escolhas de estratégias de planejamento para o ensino há um predomínio de atividades experimentais de modo que os alunos possam aprender Cinética Química a partir de estratégias que envolvem os conhecimentos da ciência e o cotidiano de seus alunos.

Para licencianda E2, foi possível observar que o modo de reflexão de um instrumento de planejamento para outro é diferente em algumas de suas ações, como a valorização do conhecimento prévio dos alunos é menos evidente em seus planos de aulas, mas articula o conhecimento do conteúdo conceitual no CoRe. Sua forma de avaliar é a observação em sala de aula, levando em conta a participação dos alunos e priorizando atividades em grupos, assim como a experimentação investigativa orientada, usando procedimentos para que seus alunos aprendam a química daquilo que esteja relacionado com o cotidiano.

A licencianda L3 possui uma orientação de Ensino de Ciências bem definida, sendo essa característica de ensino predominante em seus instrumentos de planejamento. Sua ação docente tem característica de ensino centrada em projetos, sendo suas estratégias de ensino atividades experimentais de diversos modos, objetivando relacionar sempre o conhecimento dos alunos com o cotidiano, o uso de modelização e exercícios em sala de aula. Seu modo de avaliar é a participação dos alunos e também exercícios em cada aula. A respeito da compreensão dos alunos, suas aulas procediam de articulações teóricas do conhecimento prévio dos alunos envolvendo o contexto dos mesmos com o objetivo do conteúdo estudo.

Os planejamentos de ensino se mostram como uma importante ferramenta para conduzir o que as licenciandas caracterizam importante do conhecimento de seus contextos e para o processo de reflexão sobre a ação docente, para o qual elaboraram o planejamento mobilizando diferentes conhecimentos em cada ação de ensino. 


\section{CONSIDERAÇÕES FINAIS}

Ao analisar os instrumentos de registro do estágio curricular supervisionado percebe-se que a prática de ensino desenvolvida proporcionou às estagiárias a iniciação à prática da docência, oportunizando relacionar a teoria e a prática com a realidade do cotidiano escolar e os desafios que o professor enfrenta em sala de aula. O estágio foi um momento de grande experiência para formação, foi um processo de aprendizagem, possibilitando às estagiárias refletir durante e após as regências a importância do papel do professor no processo de mediação do conhecimento e a compreensão do desenvolvimento de aprendizagem do aluno. As metas estipuladas pelas estagiárias foram cumpridas através de técnicas e instrumentos diversificados que tornaram as aulas dinâmicas e interessantes. As aulas desenvolvidas buscaram aproximar o conteúdo trabalhado com a realidade dos educandos, além de abrir espaço para uma constante troca de experiências entre alunos e professores.

A docência e outras profissões diretamente ligadas a ela implicam na necessidade de constante aprendizado e renovação e quando se iniciam as regências no estágio isso se torna bem evidente. Através dos instrumentos de planejamento de ensino das licenciandas, foi possível acessar o PCK, segundo o Modelo proposto de Magnusson, Krajick e Borko (1999). O MRPA das licenciandas, juntamente com os instrumentos de planejamento (CoRe e plano de aula) e a dinâmica interativa entre licenciandas e professores experientes (orientador e supervisor de estágio), tornam a aprendizagem da docência possível, pois as orientações para planejar e replanejar, o reconhecimento dos aspectos positivos e negativos por quem está observando a ação dos aprendizes, é uma experiência que traz olhares distintos para quem está no início de uma carreira profissional. 


\title{
Teaching planning and learning during the Supervised Internship
}

\begin{abstract}
The present work aims in the process of constructing teaching learning about teaching orientation, understanding students' ideas and the repertory of instructional and evaluative strategies of teachers in formation during the Supervised Probation period. We analyzed with the support of the content analysis methodology, the perception and reflections of three trainees on the teaching of Chemical Kinetics content from planning activities such as the lesson plan, CoRe (Content Representation) and PRA (Model of Pedagogical Reasoning and Action). The categories used in the analysis were defined a priori, videlicet: Guidelines for Science Teaching, Knowledge of Instructional Strategies, Knowledge of Science Teaching Assessment and Knowledge of Students' Understanding of Science. As main results, we pointed out that teaching planning instruments were capable of revealing most of the categories of Pedagogical Content Knowledge (PCK). When analyzing the registration's instrument of the Supervised Probation, it is possible to observes that the teaching practice developed provided the initiation to teaching, opportunizing to relate the theory and practice to the reality of everyday school and the challenges that teacher faces in the classroom class.
\end{abstract}

KEYWORDS: Supervised Internship. Chemical Kinetics. Pedagogical Content Knowledge. 


\section{REFERÊNCIAS}

ANDRADE, M. G.; FERNANDEZ, C. Planejamento e Plano de Ensino de Química para o Ensino Médio: concepções e práticas de professores em formação contínua. XIV Encontro Nacional de Ensino de Química - ENEQ. In: Anais do XIV Encontro Nacional de Ensino de Química. Curitiba-PR: 2008. Disponível em: $<$ http://www.cienciamao.usp.br/tudo/exibir.php?midia=eneq\&cod=_planejamen toeplanodeensi>. Acesso em: 10 abr. 2017.

BOGDAN, R.; BIKLEN, S. Investigação Qualitativa em Educação. Uma Introdução à Teoria e aos Métodos. Lisboa: Porto Editora (Coleção Ciências da Educação), 1994.

FERNANDEZ, C. A Base de Conhecimentos para o Ensino e o Conhecimento Pedagógico do Conteúdo (PCK) de professores de química. 329 p. Tese (Livre Docência), Universidade de São Paulo, 2014.

FERNANDEZ, C. Revisando a Base de Conhecimentos e o Conhecimento Pedagógico do conteúdo (PCK) de professores de Ciências. Revista Ensaio. Belo Horizonte. Edição 2015, v. 17, n.500-528. Disponível em:

<http://www.scielo.br/pdf/epec/v17n2/1983-2117-epec-17-02-00500.pdf>. Acesso em: 28 abr. 2017.

JUNIOR, M. M. O; NOVAIS, R. M; FERNANDEZ, C. O Instrumento "CoRe" como atividade didática para acessar o conhecimento pedagógico do conteúdo de licenciandos. XVI Encontro Nacional de Ensino de Química - ENEQ. In: Anais do XVI Encontro Nacional de Ensino de Química. Salvador-BA: 2012. Disponível em: <https://portalseer.ufba.br/index.php/anaiseneq2012/article/view/7573>. Acesso em: 23 abr. 2017.

KLINGER, M. A; BARICCATTI, R. Práticas Pedagógicas em Cinética Química. Disponível em:

$<$ www.gestaoescolar.diaadia.pr.gov.br/arquivos/File/producoes_pde/artigo_miro _alfonso_klinger.pdf>. Acesso em: 28 abr. 2017.

LEAL, S.H; NOVAIS, R. M; FERNANDEZ, C. Conhecimento Pedagógico do Conteúdo de "Estrutura da Matéria" de uma professora de química experiente em aulas de química geral. Revista Cienc. Educ. Bauru. Edição 2015, v. 21, n.725-742.

Disponível em: <http://www.scielo.br/pdf/ciedu/v21n3/1516-7313-ciedu-21-030725.pdf>. Acesso em: 20 abr. 2017.

LOUGHRAN, J.; GUNSTONE, R.; BERRY, A.; MILROY, P.; MULHALL, P. Science cases in action: developing and understanding of science teachers"pedagogical content knowledge". National Association for Research in Science Teaching, p.1-36. New Orleans, 2000. 
LOUGHRAN, J.; MULHALL, P.; BERRY, A. In search of pedagogical content knowledge in science: developing ways of articulating and documenting Professional practice. Journal of Research in Science Teaching, v.41, n.4, p.370391, 2004.

MIZUKAMI, M. G. N. Aprendizagem da docência: algumas contribuições de L. S. Shulman. Revista do Centro de Educação. Edição 2004, v.29, n.2. Disponível em: <http://coralx.ufsm.br/revce/revce/2004/02/a3.htm>. Acesso em: 20 abr. 2017.

PIMENTA, S. G. O estágio na formação de professores: unidade teoria e prática? 4. ed. São Paulo: Cortez, 2001.

PIMENTA, S. G.; LIMA, M. S. L. Estágio e docência. São Paulo: Cortez, 2008.

PORLAN, R.; MARTIN, J. El diario del profesor. Un recurso para la investigácion en el aula. Sevilla: Díada, 1997.

SALAZAR, S. F. El conocimiento pedagógico del contenido como categoría de estudio de la formación docente. Actualidades investigativas en educación, San Pedro, v. 5, n. 2, 1-18, 2005. Disponível em: <revista.inie.ucr.ac.cr>. Acesso em: 20 abr. 2017.

SHULMAN, L. S. Knowledge and Teaching: Foundations of the New Reform, Harvard Educational Review. v. 57, p.1-22, 1987.

Recebido: 29 mai. 2017

Aprovado: 21 jul. 2017

DOI: $10.3895 /$ actio.v2n1.6767

Como citar:

SANTOS, E. A. dos; FREIRE, L. I. F. Planejamento e aprendizagem docente durante o estágio curricular supervisionado. ACTIO, Curitiba, v. 2, n. 1, p. 263-281, jan./jul. 2017. Disponível em:

$<$ https://periodicos.utfpr.edu.br/actio>. Acesso em: XXX.

Correspondência:

Eliane Aparecida dos Santos

Rua Teixeira de Freitas, 682, Nova Rússia, CEP 84053-430, Ponta Grossa, Paraná, Brasil.

Direito autoral: Este artigo está licenciado sob os termos da Licença CreativeCommons-Atribuição 4.0

Internacional.

(c) (i) 